\title{
OS INSTITUTOS FEDERAIS E O DESENVOLVIMENTO REGIONAL: INTERFACE POSSÍVEL
}

\author{
L. A. C. PEREIRA ${ }^{1}$ e J. L. V. CRUZ $^{2}$ \\ Instituto Federal Fluminense ${ }^{1}$, Universidade Candido Mendes de Campos ${ }^{2}$ \\ luizcaldas.iff@gmail.com ${ }^{1}$
}

Artigo submetido em 29/11/2018 e aceito em 23/05/2019

DOI: $10.15628 /$ holos.2019.7992

\section{RESUMO}

A Educação Profissional e Tecnológica experimentou significativas transformações a partir de 2003, com a expansão da Rede Federal de Educação Profissional Científica e Tecnológica e a criação dos Institutos Federais de Educação Ciência e Tecnologia - Institutos Federais. $O$ artigo analisa as possibilidades dessas transformações em contribuir para o desenvolvimento e a integração regionais, na medida em que esta é uma das suas diretrizes. Apresenta os critérios de localização dos campi e as prerrogativas dos Institutos Federais; e discute caminhos para a contribuição da Educação Profissional e Tecnológica e dos Institutos Federais ao desenvolvimento regional. Constata-se que os critérios de localização dos novos campi possibilitaram a sua difusão em regiões periféricas e em mesorregiões que podem ter a sua dinâmica socioeconômica positivamente impactada, numa perspectiva de políticas intersetoriais voltadas para o desenvolvimento regional.

PALAVRAS-CHAVE: Educação Profissional, Instituto Federal, Desenvolvimento Regional, Expansão, Interiorização.

\section{THE FEDERAL INSTITUTES AND THE REGIONAL DEVELOPMENT: POSSIBLE INTERFACE}

\begin{abstract}
Professional and Technological Education has undergone significant changes since 2003, its highlights being the expansion of Professional Scientific and Technological Education Federal Network and the creation of the Federal Education, Science and Technology Institutes-FI. The article analyzes possibilities of those changes regarding their contribution to regional development and integration, as long as it is part of their guidelines. It presents Federal Institutes campuses location criteria
\end{abstract}

and their prerogatives; and discusses paths to take regarding $\mathrm{PTE}$ and $\mathrm{FI}$ contribution to regional development. It finds out that its location criteria allowed regionalised interiorization and diffusion in peripheral regions and in mesoregions which may have socioeconomic dynamics and development positively impacted, in regional development intersetorial politics perspective.

KEYWORDS: Professional Education, Federal Institute, Regional Development, Expansion, Interiorization. 


\section{INTRODUÇÃO}

Na discussão sobre o desenvolvimento brasileiro, em uma sintonia com a leitura histórica, dois movimentos importantes no século XX podem ser destacados neste artigo: o processo de industrialização no curso da expansão do sistema capitalista em sua periferia e suas implicações no ordenamento territorial.

O Brasil investiu na industrialização com forte presença do Estado e, inicialmente, sob o modelo de substituição de importações, a exemplo de grande parte dos países latino-americanos, projetou uma maior homogeneização do seu território no decorrer do tempo. O resultado de tais investimentos contribuiu, de fato, para a construção de uma sólida e diversificada base industrial, porém não logrou o mesmo êxito em construir um país territorialmente caracterizado por um desenvolvimento integrado e pouco desigual, em termos regionais e sociais. (CANO, 2008; OLIVEIRA, 2010; TAVARES, 1972)

O objetivo deste trabalho, tendo como pano de fundo a dinâmica regional, é discutir a política de educação profissional a partir de 2003, com foco na expansão da Rede Federal de Educação Profissional Científica e Tecnológica (Rede Federal) e na criação dos Institutos Federais, dada a natureza e a dimensão territorial dessas políticas, apontando possibilidades em contribuir com o desenvolvimento regional, como equipamentos e recursos públicos capazes de avançar em direção a uma maior integração das escalas subnacionais.

A educação profissional sempre esteve permeada pela disputa entre duas concepções distintas, cujo perfil esquemático seria: de um lado, a defesa de um processo formativo comprometido com a qualificação para o trabalho articulada a uma visão crítica, humanista, holística. Nesta ótica, o investimento em educação profissional se justifica enquanto direito das pessoas à educação e à formação para o trabalho, sob uma concepção inclusiva, de desenvolvimento voltado para a redução das desigualdades sociais e territoriais. De outro, a capacitação numa visão empresarial, utilitarista e instrumental, restrita às demandas de produtividade e rentabilidade do capital. Nessa perspectiva, no limite, as instituições de representação empresarial teriam papel decisivo nas definições de conteúdos e das grades de disciplinas, considerando a educação profissional como objeto da atividade empresarial, ainda que em parceria com o Estado, contrariamente a uma política pública de amplo alcance, para além da formação para o trabalho, em sentido restrito.

O artigo analisa a expansão da Rede Federal e a criação dos Institutos Federais e discute, de forma embrionária, as implicações e possibilidades potenciais da nova configuração espacial desta Rede para o desenvolvimento regional, na perspectiva da integração inter e intrarregional.

O referencial teórico-metodológico pesquisado - publicações sobre a temática da Educação Profissional e Tecnológica, legislações e documentos oficiais do Ministério da Educação -MEC busca destacar a relação da política de expansão da Rede Federal e de criação dos Institutos Federais com as possibilidades que podem emergir em favor do desenvolvimento regional e da integração territorial. Os dados provenientes da implantação dos campi nas fases da expansão que 
geraram as tabelas, os gráficos e os mapas, foram coletados nos portais institucionais; os relativos às matrículas, extraídos do Censo da Educação Básica no portal do Instituto Nacional de Estudos e Pesquisas Educacionais Anísio Teixeira - INEP.

O texto está organizado em quatro seções que abordam, respectivamente: a introdução, a expansão da Rede Federal e a criação dos Institutos Federais enquanto política nacional de base regional e os critérios locacionais que valorizam a dimensão territorial; as possibilidades de formulação de alternativas no campo do desenvolvimento que considerem as múltiplas realidades territoriais do país e as atribuições dos Institutos Federais, e por fim nas considerações finais, destacam-se os pontos mais relevantes propostos no artigo.

\section{A POLÍTICA de EXPANSÃO dA REDE FEDERAL DE EDUCAÇÃO PROFISSIONAL, CIENTÍFICA E TECNOLÓGICA A PARTIR DE 2003}

A Educação Profissional e Tecnológica experimentou transformações na primeira década deste século, dentre as quais se destacam o plano de expansão da Rede Federal e a criação dos Institutos Federais. Entre 2003 e 2015, houve um significativo aumento no número de matrículas nas instituições federais de Educação Profissional e Tecnológica: das 79.484 matrículas no nível médio técnico em 2003, chega-se a 325.097, em 2015; no ensino superior, de 33.801 matrículas, em 2003, atinge-se um total de 144.876, em 2015, segundo o Censo da Educação Básica (INEP).

Embora, neste período, outras iniciativas governamentais com ênfase na ampliação do acesso à educação profissional se estabelecessem como diretrizes das deliberações políticas do MEC tais como o Programa Brasil Profissionalizado ${ }^{1}$ e o Sistema Escola Técnica Aberta do Brasil ${ }^{2}$ (e-Tec Brasil), neste artigo, a abordagem recairá, especificamente, sobre a expansão da Rede Federal e a criação dos IF, buscando examinar seus desdobramentos territoriais.

Os Institutos Federais, criados por meio da Lei № 11.892/2008, são instituições de educação superior, básica e profissional, de natureza jurídica autárquica, detentoras de autonomia financeira, administrativa, patrimonial e didático-pedagógica, cujas atividades-fim incluem formação de profissionais nos diferentes níveis, desde os cursos de qualificação básica até os de pós-graduação stricto sensu, além do desenvolvimento de pesquisa aplicada e extensão tecnológica. Atribuições que possibilitam diversas alternativas em relação tanto à inserção no mundo do trabalho quanto à contribuição ao desenvolvimento, como se verá adiante.

Dentre os níveis e modalidades de educação profissional, ofertadas pelos IF, a formação de técnicos de nível médio merece, neste ponto, uma análise sensível tendo em vista que a formação de técnicos (qualificação profissional associada ao desempenho de funções intermediárias nos processos de produção e serviços) representa mais do que uma opção ditada pelo mercado; é uma necessidade, nos países capitalistas periféricos, para um expressivo número de jovens, submetidos a um processo de desenvolvimento, ao longo da história, política e estruturalmente incompatível com a ampliação de direitos, da cidadania e da justiça social, que precisam antecipar o ingresso no

\footnotetext{
${ }^{1}$ Decreto N.ㅇ 6.302/2007.

2 Decreto N.ㅇ 7.589/2011.
} 
mercado de trabalho e participar da sobrevivência de suas famílias. Associada a essa oferta de formação profissional, de modo intrínseco, encontra-se o desenvolvimento da pesquisa aplicada e promove-se a ampliação e democratização do acesso ao conhecimento científico e tecnológico por meio de atividades de extensão.

No discurso empresarial, instrumental, a formação do técnico é restrita à 'técnica', como única e melhor contribuição ao desenvolvimento. Neste estudo, no entanto, destaca-se o diferencial perseguido pelos Institutos Federais que é promover formação técnica de base holística, humanística, multidisciplinar, para um desenvolvimento com distribuição de renda, direitos e segurança no trabalho e na vida, justiça social e cidadania plena.

A formalização da Rede Federal $^{3}$ e a criação dos Institutos Federais ensejaram debates que culminaram na expansão da oferta da Educação Profissional e Tecnológica numa perspectiva de ação integrada dentro de uma mesma política. Isso significa que, para trilhar o caminho que leva aos Institutos Federais, passamos, necessariamente, pela política de expansão de base territorial. Entende-se que tais políticas podem assumir significativo papel no desenvolvimento regional pela possibilidade de fazer chegar esse equipamento público a todas as mesorregiões brasileiras, via implantação de unidades vinculadas a uma tipologia institucional que pode torná-las estratégicas para a transformação econômica e social, visto que essas instituições representariam função do Estado na implantação e desenvolvimento de uma política de educação profissional (ORTIGARA, 2014).

Para melhor situar esta relação dos Institutos com a temática do desenvolvimento regional, é importante recorrer à lei de sua criação, às atribuições dessas instituições. É importante observar que a lei, como um todo, assimila a questão da territorialidade no âmbito do desenvolvimento. Já no seu art. 2o define os Institutos Federais como instituições multicampi, do que se pode inferir a atuação sistêmica de seus campi, no limite de sua área territorial de abrangência. Assim, a lei estabelece aos Institutos Federais a obrigação de se colocar de forma efetiva no seu território

$\S 3$ ㅇ do Art. 2ㅇ. - Os Institutos Federais terão autonomia para criar e extinguir cursos, nos limites de sua área de atuação territorial, bem como para registrar diplomas dos cursos por eles oferecidos, mediante autorização do seu Conselho Superior, aplicando-se, no caso da oferta de cursos a distância, a legislação específica (BRASIL, 2008).

$\mathrm{O}$ art. 60 trata das finalidades e características dos Institutos, nos incisos I, IV, VII, VIII e IX. $\mathrm{O}$ inciso I traz a questão da oferta educativa de forma mais ampla e as possibilidades geradas pelo maior acesso aos serviços educacionais em diversas escalas, seja local, regional ou nacional. 0 inciso II articula ensino e pesquisa na perspectiva da produção do conhecimento que responda às demandas sociais, considerando as singularidades econômicas, sociais e culturais de cada região.

\footnotetext{
${ }^{3}$ A denominação Rede Federal sempre foi usada como referência ao conjunto de instituições federais vinculadas ao MEC, que atua na oferta de educação profissional e tecnológica. No entanto, é com a Lei N.o11.892/2008 que se cria a Rede Federal.
} 
O inciso IV enfatiza o apoio às estruturas socioculturais locais, inclusive com uma metodologia para esse apoio: "o diagnóstico das oportunidades de desenvolvimento seguido da sintonização da oferta educativa com essas potencialidades, de forma a contribuir para a composição e consolidação de arranjos locais para o incremento da produção, fortalecimento da organização social e das identidades culturais". A integração estratégica entre ensino, pesquisa e extensão e o destaque para a questão ambiental está apontada nos três últimos incisos. Enquanto política de base regional, os Institutos Federais dialogam, assegurada sua autonomia, com diversas representações locais e regionais.

Art. 9 - Cada Instituto Federal é organizado em estrutura multicampi, com proposta orçamentária anual identificada para cada campus e a reitoria, exceto no que diz respeito a pessoal, encargos sociais e benefícios aos servidores (BRASIL, 2008).

Ao organizar as instituições da Rede em estrutura multicampi, a lei definiu que a proposta orçamentária anual fosse identificada para cada campus e a reitoria, como forma de garantir que cada unidade gerisse seus próprios recursos, uma vez que elas possuem condições melhores de planejar seus investimentos para atender aos interesses das regiões onde estão inseridas e, desta forma, contribuir para reduzir as desigualdades socioeconômicas regionais. A autonomia na gestão orçamentária e financeira se faz como condicionante ao cumprimento de sua função social (SILVA, 2009).

Dentro da lógica de acostamento com as regiões, é importante ressaltar que, no processo de implantação de novos campi, a aproximação com o contexto regional se faz a partir da escuta às comunidades e suas representações, por meio de audiências públicas. Adota-se este instrumento para apresentar a instituição (seu histórico e áreas de atuação), propiciar a participação de segmentos da sociedade para a construção de uma instituição comprometida com a região, recolher sugestões que permearão as ações do campus e oportunizar a identificação dos possíveis cursos técnicos e superiores a serem implantados. Esses expedientes, ainda que tenham fragilidades, constituem importantes instrumentos de valorização da apropriação do espaço público pela comunidade, realçando o sentido de pertencimento. As audiências públicas são mecanismos garantidos pela Constituição de 1988 e devem ser utilizadas pelo poder público para garantir as práticas democráticas.

O efeito combinado da capilaridade e da interiorização no processo de expansão da educação profissional provocou mudanças na configuração da Rede Federal no território brasileiro, sendo determinante para a territorialização desta política educacional. A aderência territorial faz com que o conjunto das instituições da Rede potencialize suas ações no ensino, na pesquisa e na extensão, para contribuir na dinâmica das diferentes regiões brasileiras, buscando articular e integrar, em múltiplas escalas espaciais, as potencialidades locais nos territórios ainda não contemplados pelo movimento econômico dominante no país com os programas e equipamentos educacionais e produtivos.

Essa iniciativa pode impulsionar a integração dessas cidades na economia nacional e à dinâmica estadual e regional, por vias alternativas ou não, apoiadas nos recursos locais, micro e 
mesorregionais, por serem capazes de criar redes de circuitos econômicos, urbanos e sociais. Uma combinação de fatores que pode alcançar, sobretudo, os não contemplados como "ilhas dinâmicas", e que, por isso, demandam políticas públicas elaboradas com vistas à aproximação dos equipamentos e estruturas educacionais com as produtivas.

A expansão foi organizada em três etapas: na fase I, implantação de 64 (sessenta e quatro) novas instituições; 150 (cento e cinquenta), na fase II; e 208 (duzentos e oito) unidades na fase III, com base em critérios de localização por etapa. Esses critérios se basearam em diretrizes (Quadro 1), que visaram o equilibro espacial da oferta da Educação Profissional e Tecnológica no país e a articulação entre políticas e projetos das áreas sociais, educacionais, produtivas e econômicas.

Quadro 1: Critérios locacionais de implantação de unidades da Rede Federal no Plano de Expansão

\begin{tabular}{|c|c|l|}
\hline Fase & Período & \multicolumn{1}{|c|}{ Critério } \\
\hline I & 2005/2007 & $\begin{array}{l}\text { 1) unidades da Federação que não possuíssem nenhuma escola da Rede } \\
\text { Federal; } \\
\text { 2) regiões mais interioranas do país; } \\
\text { 3) periferias dos grandes centros urbanos. }\end{array}$ \\
\hline II & $\begin{array}{l}\text { 1) distribuição territorial equilibrada das novas unidades (evitando a } \\
\text { concentração de unidades em regiões mais bem contempladas); } \\
\text { 2) cobertura do maior número possível de mesorregiões; } \\
\text { 3) sintonia com os Arranjos Produtivos Locais; } \\
\text { 4) aproveitamento de infraestruturas físicas existentes; } \\
\text { 5) identificação de potenciais parcerias; } \\
\text { 6) atendimento às demandas provenientes das políticas de } \\
\text { desenvolvimento industrial, de geração de trabalho e renda, de } \\
\text { modernização e expansão do agronegócio, de fortalecimento do trading } \\
\text { turístico, de fomento às novas formas de associação e cooperativismo, de } \\
\text { desenvolvimento de arcos produtivos com elevado grau de inovação } \\
\text { tecnológica. }\end{array}$ \\
\hline III & $\begin{array}{l}\text { 1) erradicação da pobreza (Territórios da Cidadania4, municípios com } \\
\text { elevado percentual de pobreza); } \\
\text { 2) interiorização (macrorregiões não atendidas); } \\
\text { 3) grandes obras do PAC Arranjos Produtivos Locais. }\end{array}$ \\
\hline
\end{tabular}

Fonte: Elaboração própria.

A relação entre a expansão da educação profissional, as políticas de desenvolvimento e a localização das escolas sempre existiu, em maior ou menor grau e segundo interpretações diversas, em se tratando da Rede Federal, o que pode ser ilustrado colocando em destaque três momentos: um primeiro, instituído pelo Decreto 7.566/1909 que cria a Escolas de Aprendizes Artífices -EAA, origem da atual Rede Federal, nos primórdios da industrialização brasileira, que estabelecia a localização de uma escola em cada capital dos estados da federação com até cinco

\footnotetext{
4 Território da Cidadania é formado por um conjunto de municípios com mesmas características econômicas e ambientais que tenham identidade e coesão social, cultural e geográfica. Maiores que o município e menores que o estado, os territórios conseguem demonstrar a realidade dos grupos sociais, das atividades econômicas e das instituições de cada localidade, o que facilita o planejamento de ações governamentais para o desenvolvimento dessas regiões. Foram definidos 120 Territórios até 2010 (BRASIL, 2009).
} 
oficinas de trabalho manual ou mecânico mais convenientes e necessárias ao Estado, segundo as especialidades das indústrias locais; um segundo, o Programa de Expansão e Melhoria do Ensino Técnico -PROTEC, lançado em 1986, com a meta de implantar duzentas escolas técnicas e agrotécnicas no Brasil, tendo como prioridade as cidades do interior. De acordo com Queiroz e Souza (2017) essa iniciativa inseriu-se no bojo da implantação do I Plano Nacional de Desenvolvimento da Nova República, I PND (1986-1989); e, num terceiro momento, a expansão a partir de 2003, objeto desse artigo que, como já anotado, está inserido no contexto dos princípios e diretrizes norteadores da PNDR-Política Nacional de Desenvolvimento Regional. Esta foi criada pelo Decreto 6.047/2017, conhecida como PNDR I, e ampliada em 2012, na Conferência Nacional de Desenvolvimento Regional, que aponta para a Nova Política ou PNDR II (Brasil, 2007; BRANDÃO, 2014).

Sem descartar fatores alheios aos critérios norteadores das políticas de desenvolvimento (clientelismo e pressão política, por exemplo), parece razoável afirmar que a constituição e evolução da Rede Federal estiveram inseridas ou refletidas nos objetivos das políticas de desenvolvimento. Neste artigo, enfatiza-se a caracterização do contexto inerente ao terceiro momento, quando são introduzidos, nessa política, elementos que vão além da exclusividade da influência dos interesses puramente empresariais e do mercado, incorporando aspectos referentes às prioridades de um projeto nacional que tem como questão central a busca da superação das desigualdades.

A Figura 1 apresenta a densidade espacial da Rede Federal antes da expansão recente, em que a maior dispersão, em alguns estados, não representa apenas a existência de um número menor de unidades, mas o reflexo do desenvolvimento brasileiro, caracterizado por uma concentração de equipamento público, de educação, ciência e tecnologia, etc. ao longo do litoral, nas capitais e em torno de algumas "ilhas de prosperidade". A Figura 2 mostra a Rede Federal com a incorporação das unidades implantadas até o ano de 2014 , atestando o impacto sobre o território brasileiro, com maior adensamento em direção às regiões interioranas e periféricas.

Levantamentos junto ao portal do MEC e nos sites das instituições revelam que a Rede Federal, em 2016, estende-se por todo o território brasileiro, em 558 municípios, com 601 unidades, alcançando novos espaços sub-regionais. 


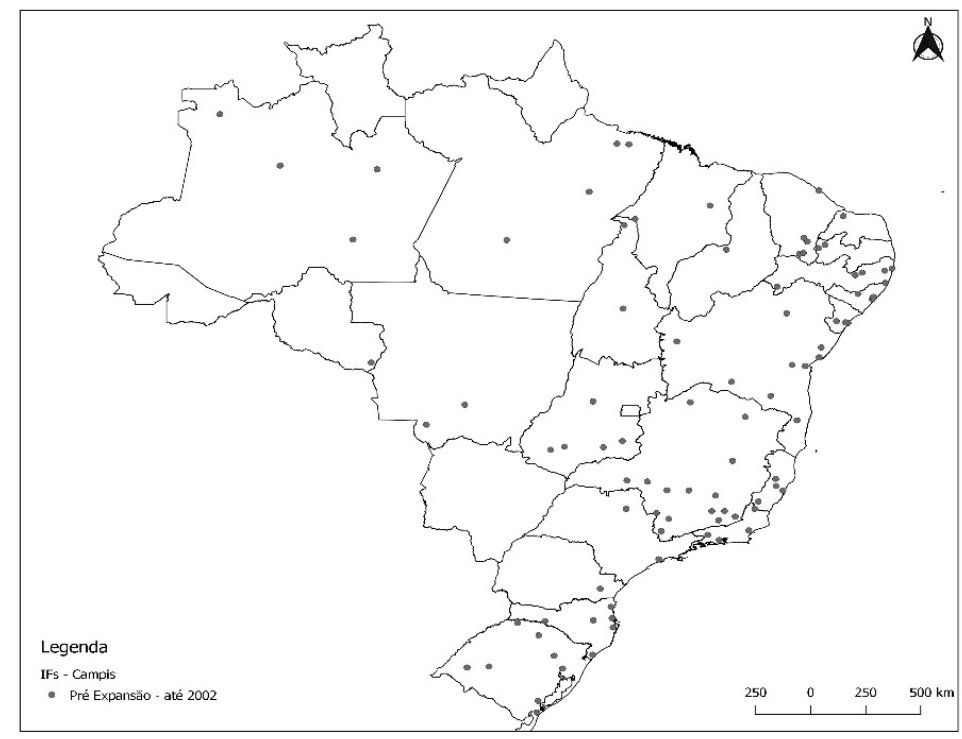

Fonte: Elaboração própria.

Figura 1: Unidades da Rede Federal de Educação Profissional Científica e Tecnológica na fase pré-expansão

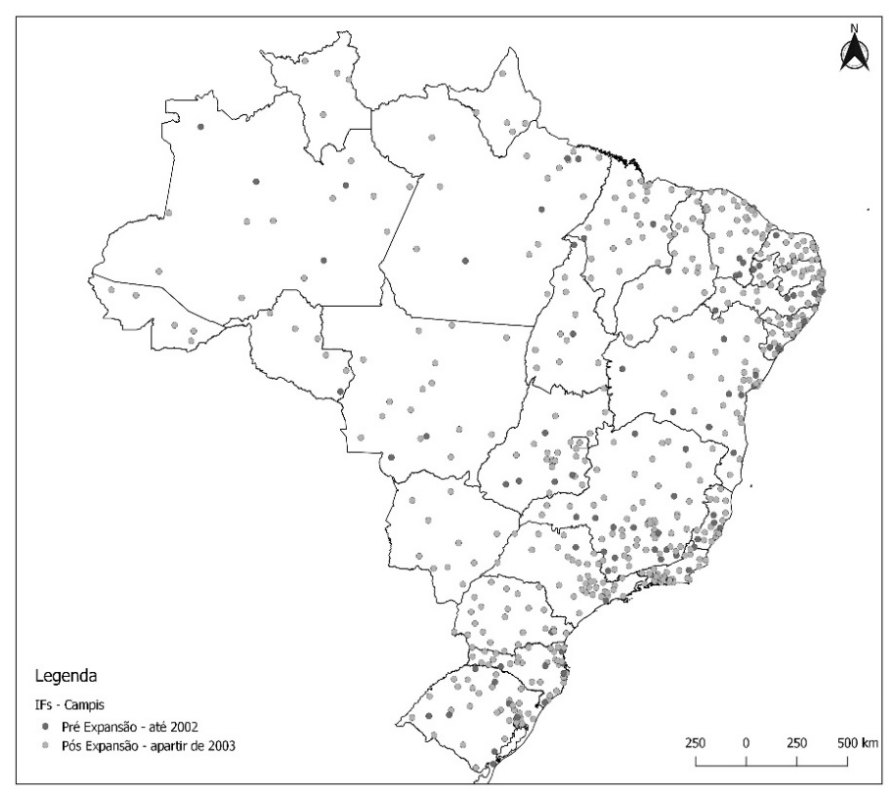

Fonte: Elaboração própria.

Figura 2: Unidades da Rede Federal de Educação Profissional Científica e Tecnológica na fase pósexpansão.

Este processo de desconcentração geográfica da Rede Federal converge com as transformações espaciais (produtiva e demográfica) do país nos primeiros anos do século XXI. Segundo Diniz (2006, p. 10), o mapa que resulta dessas mudanças revela que "está em curso uma nítida mudança no padrão territorial do país", que combina, às novas tendências produtivas, novas 
dinâmicas territoriais da população, formação de redes urbanas e metrópoles, que podem ser identificadas.

[...] um novo e diversificado mapa populacional, social e produtivo do país, onde já não se pode caracterizar a nítida divisão entre o litoral e o interior, nem entre o campo e a cidade ou tampouco entre as macrorregiões. Embora ainda fortemente concentrado no Sudeste e no Sul, o que se observa é a formação de um grande número de áreas produtivas em várias partes do país, em setores diversificados, caracterizando um Brasil ao mesmo tempo integrado e diversificado Pacheco (1998 apud Ibid.).

A política de expansão seguiu dois vetores: a regionalização, com uma distribuição de unidades que possibilitou maior capilaridade na oferta de educação profissional; e a territorialização, com a perspectiva de enraizamento do desenvolvimento, buscando reconhecer, articular e incluir, em sentido amplo, as práticas, tradições e experiências locais e regionais no contexto de decisões sociais e econômicas, vinculando-as ao ensino profissional. Nesse sentido, a expansão da Rede Federal, como política nacional de base territorial, se coloca no contexto das iniciativas que visam contribuir para a redução da fragmentação e de hiatos territoriais que marcam a trajetória do desenvolvimento brasileiro.

No entanto, considerando o objetivo desta seção, de traçar uma visão panorâmica atual da Rede Federal após o processo de expansão na perspectiva de estabelecer relações com o perfil regional do desenvolvimento, serão analisados, apenas, os Institutos Federais e os Centro Federais de Educação Tecnológica - CEFET. As demais instituições da rede - Universidade Tecnológica Federal do Paraná, Escolas Técnicas Vinculadas às Universidades Federais e Colégio Pedro II - não serão abordadas neste momento.

Em termos de desdobramentos sub-regionais e intraestaduais, como resultado das fases da expansão, constata-se, na Figura 3, que todos os estados contam com diversas unidades vinculadas aos 38 Institutos Federais e 02 CEFETs. É importante observar a inexistência de unidades da Rede Federal no Acre, Amapá, Mato Grosso do Sul e Distrito Federal, antes de 2003.

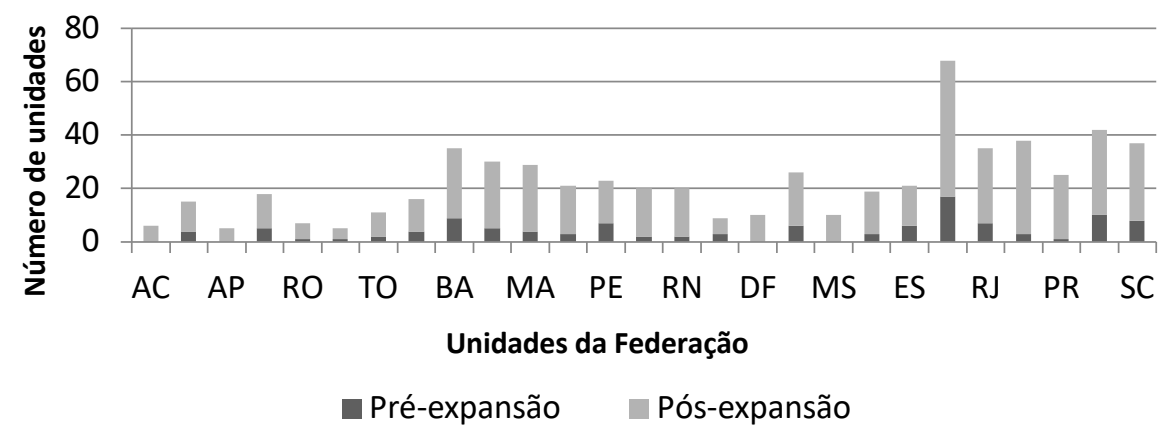

Fonte: Elaboração própria.

Figura 3: Distribuição dos campi da Rede Federal pelas unidades da Federação - 2002/2016 
Constata-se, assim, conforme a Tabela 1, a seguir, a abrangência do plano de expansão, ao contemplar todas as regiões brasileiras, com 488 novos campi. A macrorregião Centro-Oeste, ao agregar 56 novos campi, tornou-se mais de sete vezes maior em 2016, registrando o mais expressivo crescimento relativo dentre as cinco macrorregiões. Esta região, no período consolidou-se como o maior centro do agronegócio brasileiro, o que reforça a análise deste artigo. Nas regiões Norte, Nordeste, Sudeste e Sul a Rede Federal quintuplicou.

Tabela 1: Brasil e regiões: distribuição dos campi da Rede Federal -2002/2016

\begin{tabular}{lllll}
\hline \multirow{2}{*}{ Brasil e região } & \multicolumn{2}{c}{$\mathbf{N}$. de campi } & \multicolumn{2}{c}{ \% de campi } \\
\cline { 2 - 5 } & $\mathbf{2 0 0 2}$ & $\mathbf{2 0 1 6}$ & $\mathbf{2 0 0 2}$ & $\mathbf{2 0 1 6}$ \\
\hline Brasil & 113 & 488 & 100 & 100 \\
Norte & 13 & 54 & 11,50 & 11,07 \\
Nordeste & 39 & 164 & 34,51 & 33,61 \\
Sudeste & 33 & 129 & 29,20 & 26,43 \\
Sul & 19 & 85 & 16,81 & 17,42 \\
Centro-Oeste & 9 & 56 & 7,96 & 11,47 \\
\hline
\end{tabular}

Fonte: Elaboração própria.

A seguir, apresenta-se os dados sobre a desconcentração intrarregional, com a implantação dos campi, em relação a todas as mesorregiões brasileiras, de acordo com a classificação do Instituto Brasileiro de Geografia e Estatística - IBGE. Do total de 137, somam 135 as mesorregiões contempladas (ficaram de fora Marília e Assis, no estado de São Paulo). A relevância desta política não se funda, apenas, no tônus quantitativo, mas, principalmente, em seus vetores de interiorização, na medida em que se procurou sintonizar a oferta de um equipamento estratégico, na sua concepção e nos seus objetivos, com políticas distributivas e sociais de cunho territorial, como se deu com a incorporação das áreas cobertas pelo Território da Cidadania como um dos critérios.

Tabela 2: Distribuição de campi da Rede Federal nas mesorregiões

\begin{tabular}{l|c|c|c|c}
\hline \multicolumn{1}{c|}{ Região } & $\begin{array}{c}\text { N.o de } \\
\text { mesorregiões }\end{array}$ & $\begin{array}{c}\text { N.o de } \\
\text { mesorregiões } \\
\text { mesorregiões } \\
\text { com campi no } \\
\text { período pré- } \\
\text { expansão }\end{array}$ & $\begin{array}{c}\text { Nom de novas } \\
\text { período pós- } \\
\text { expansão }\end{array}$ & $\begin{array}{c}\text { mesorregiões } \\
\text { atendidas no período } \\
\text { pós-expansão }\end{array}$ \\
\hline Norte & 20 & 9 & 20 & 11 \\
Nordeste & 42 & 25 & 42 & 17 \\
Sudeste & 37 & 17 & 35 & 18 \\
Centro-Oeste & 15 & 3 & 15 & 12 \\
Sul & 23 & 12 & 23 & 11 \\
\hline Total & 137 & 66 & 135 & 69 \\
\hline
\end{tabular}

Fonte: Elaboração própria.

Das 488 novas unidades, $94 \%$ estão localizadas fora das capitais. Em um país heterogêneo e desigual como o Brasil, como afirma Bacelar (2013), esta penetração da Rede em regiões 
interioranas e periféricas pode vir a constituir, se articuladas com outras políticas públicas, no médio prazo, num recurso estratégico para as políticas de redução das desigualdades regionais.

Devido ao pouco tempo de existência da PNDR e às dificuldades inerentes à sua efetiva implantação (BRANDÃO, 2014), bem como ao caráter inovador dos Institutos Federais, em sua alta complexidade, além, igualmente, do caráter recente da sua implantação, no esforço de constituirse enquanto um dos recursos estratégicos para o desenvolvimento regional e local, a análise das potencialidades desse equipamento público para os fins a que se propõe, no campo do desenvolvimento territorial, não pode ir além das considerações sobre sua institucionalidade vis $a$ vis as demandas do enfrentamento das desigualdades regionais.

\section{EDUCAÇÃO PROFISSIONAL E DESENVOLVIMENTO REGIONAL}

Para melhor situar esta relação dos Institutos com a temática do desenvolvimento regional, é importante recorrer à lei de sua criação, às atribuições dessas instituições. É importante observar que a lei, como um todo, assimila a questão da territorialidade no âmbito do desenvolvimento.

Art. 60 - Os Institutos Federais têm por finalidades e características:

I - ofertar educação profissional e tecnológica, em todos os seus níveis e modalidades, formando e qualificando cidadãos com vistas na atuação profissional nos diversos setores da economia, com ênfase no desenvolvimento socioeconômico local, regional e nacional (BRASIL, 2008).

Abordagens de diferentes e confrontantes matizes ideológicas tratam da relação entre educação e desenvolvimento, desde a sua contribuição na indução e consolidação do crescimento econômico até à promoção da equidade e da inclusão social, numa relação complexa, temática que o espaço deste artigo não permite aprofundar. Isto não significa desconsiderar as contradições e os interesses diversos que permeiam esse campo, muito menos perder de vista a realidade hegemonizada pela dissimulada retórica de defesa da educação por parte de expressivas representações das elites políticas e econômicas. Essas forças atuam, no atual estágio do funcionamento do sistema capitalista, voltadas, exclusivamente, segundo Bruno (2011), para o aumento de produtividade e o incremento da mais valia relativa, para o que é fundamental uma força de trabalho mais qualificada, com maior capacidade de raciocínio e criatividade, o que não corre pari passu com as condições de trabalho e valorização do trabalhador, submetido às formas atualizadas de desregulamentação trabalhista e da seguridade, exacerbando a insegurança, a competição individual e a precarização das relações (ANTUNES, 2000).

Ao mesmo tempo, segundo Piquet (2007), o advento das novas tecnologias pôs por terra a possibilidade de o país continuar a crescer sem melhoria na capacitação dos trabalhadores. A educação assumiu enorme importância como um dos elementos da competitividade sistêmica, que passou a constituir fator de relevância nas decisões das empresas sobre a localização dos investimentos. Assim, se nova solidariedade social se impuser, não será por questões humanitárias, morais ou religiosas, mas pelas exigências do avanço sistêmico da acumulação, uma 
vez que a baixa qualificação da mão de obra em nosso país representa um entrave para a conquista da competitividade (Ibid., p. 129). Chamamos a atenção, no entanto, que tal solidariedade apenas se realiza com políticas públicas de proteção ao trabalho, seguridade social e direitos de cidadania universais.

A proposta deste artigo é, pois, sem desconsiderar a complexidade da temática que marca as relações entre educação e desenvolvimento, refletir sobre a questão regional e a Educação Profissional e Tecnológica, a partir da política de expansão da Rede Federal, a fim de contribuir para o debate que valoriza intervenções a favor do desenvolvimento regional e redução dos hiatos territoriais no Brasil.

No Brasil, o fortalecimento da relação entre educação e desenvolvimento tem que enfrentar questões decorrentes das assimetrias estruturais no padrão territorial. No entanto, é fundamental não ceder à improcedente visão que, nessa relação, atribui exagerado poder e descabido protagonismo à educação, enquanto dimensão capaz de, por si só, afiançar a realização do desenvolvimento. Sua consecução deve ser ponderada com as hierarquias institucionais, políticas e aspectos legais e macroeconômicos que implicam limites e condições específicas aos agentes que tomam decisões e iniciativas em nome da Educação.

Ressalte-se que a criação dos Institutos e a ampliação do número de unidades da Rede Federal já reduzem desigualdades de oportunidades educacionais nos níveis básicos e no ensino superior e proporcionam a produção de conhecimento em todas as mesorregiões brasileiras. Processo que representa um contraponto às tendências que um conjunto de autores, como Bacelar (2013), aponta como herança resistente do desenvolvimento brasileiro, que é a concentração costeira, não só em contingente populacional, como nas aglomerações produtivas, de infraestrutura e de instituições produtoras de conhecimento.

Brandão (2014) ressalta que, apesar de a expansão territorializada da educação se somar a uma desconcentração relativa em curso desde os anos 1970/1980, isoladamente, essas instituições não são capazes de alterar o padrão estrutural de desigualdade que depende de políticas integradas, planejadas a curto, médio e longo prazo, de base multissetorial e regional, referenciadas num projeto nacional.

Ao destacar a relação dos Institutos Federais com o desenvolvimento regional, a questão central se impõe: qual o papel que podem assumir os Institutos Federais para a promoção do desenvolvimento regional?

A reflexão que a questão enseja implica numa condição básica: a de o Institutos Federais ultrapassar os seus "muros" e interagir com a realidade de seu entorno, de modo a compreendê-la e a integrar-se no processo de desenvolvimento socioeconômico enquanto política pública, em suas diversas formas de atuação, propulsora de ações de cidadania e de justiça social.

É fundamental que os Institutos Federais avancem na perspectiva de democratizar o acesso a jovens e adultos em relação a cursos e espaços educacionais e culturais, um dos principais meios de promoção da mobilidade social nas sociedades modernas. Em particular, àqueles que, em face das condições socioeconômicas, necessitam antecipar o ingresso no mercado de trabalho ou nele manter-se. 
Fortalecer a relação dos Institutos com a educação básica é também uma das possibilidades e condição dessas instituições, do ponto de vista de ações fomentadoras do desenvolvimento. Neste caso, vários são os caminhos, a exemplo da ampliação e consolidação da oferta de licenciaturas e cursos de formação continuada para o exercício do magistério. Articularse com outras políticas, como as de cunho social, é outro fator determinante para a contribuição destas instituições ao desenvolvimento.

Sob o vértice do desenvolvimento regional, a presença dos campi dos Institutos Federais favorece um novo ordenamento territorial, na medida em que suas atividades finalísticas podem fomentar o planejamento e a definição de novos fluxos de investimentos, alterando tendência concentradora e tradicional em regiões providas de equipamentos públicos e privados, de Ciência e Tecnologia, e contribuir para elevar a capacidade produtiva de geração de trabalho e renda com retorno regional - aumentando a participação no mercado local, ou a inserção em circuito econômico mais amplo, de atividades limitadas, a princípio, às demandas locais, contribuindo, dessa forma para a integração e coesão social e produtiva de economias locais em escala nacional/internacional. Ou seja, trata-se de tratar a Educação Profissional e Tecnológica como fator de indução, suporte e elaboração de políticas de desenvolvimento voltadas para a integração territorial.

De acordo com Vieira (2017, p. 280), o estudo de Mille (2004) contribuiu para a compreensão dos impactos no desenvolvimento econômico de seus territórios decorrentes da instalação de uma Instituição de Ensino Superior - IES. Sob esse prisma, é possível identificar dois tipos de impactos: o primeiro, de curto prazo, denominado "encadeamento para trás", envolve os fluxos financeiros e monetários que resultam das despesas de estudantes, servidores técnicoadministrativos e professores com a aquisição de bens e serviços, gerando impacto no mercado local, com desdobramento para as famílias, as firmas e os governos. Esses impactos não seriam lineares, mas segundo cada um dos segmentos: as famílias seriam diretamente alcançadas via renda e emprego; as firmas teriam as demandas por suas atividades expandidas, porém poderiam ter seus custos aumentados em função da elevação da concorrência adicionada pela busca da instituição por mão de obra, imóveis, dentre outros; já os governos aumentariam a arrecadação de tributos e, em contrapartida, teriam que arcar com o incremento de demanda por infraestrutura e serviços públicos.

Para Mille (2004 apud Ibid., p. 282), a presença de uma IES também provoca "encadeamento para frente", ao influenciar, de forma gradativa e cumulativa, e assegurar as condições favoráveis, no longo prazo, a transformação estrutural das bases produtivas e econômicas de uma região. Este processo é resultante dos benefícios derivados da produção e difusão de conhecimento, presença de mão de obra qualificada, garantia de condições materiais acadêmicas para o desenvolvimento de pesquisa e ampliação do acervo local de conhecimento, principalmente, em função das interações a serem estabelecidas entre a IES e o setor produtivo (Ibid., p. 282)

A abrangência territorial dos Institutos Federais favorece a sintonia com a diversidade regional, destino privilegiado de seu trabalho e, ao mesmo tempo, possibilita que essas instituições se coloquem diante de múltiplas alternativas. É importante que, mediante hierarquias 
e prerrogativas dos diferentes atores envolvidos com as políticas de desenvolvimento, possam ultrapassar aspectos estritamente econômicos. Os níveis de qualificação dos profissionais envolvidos e do ensino proporcionado pode afetar positivamente os quadros políticoadministrativos do Poder Local, contribuindo para o fomento a uma cultura de construção de políticas e de ação pública planejada, às escalas sub-nacionais, sub-regionais e locais.

O 'encadeamento para frente' a que se refere Mille pode encontrar maior relevância na medida em que os Institutos Federais ampliem o seu escopo de atuação com vistas a articular um desenvolvimento que, no plano regional, reconheça além das dimensões social e econômica, a cultural e a ambiental. No entanto, para que esses encadeamentos ocorram, é preciso uma ação articulada, pluri-institucional, planejada, com diagnóstico das condições materiais e imateriais. Seu grau de sucesso vai depender das articulações territoriais, entre municípios e micro e mesorregiões, que rompam com o ciclo das guerras entre os lugares por benesses aos investimentos, nas quais todos perdem (VAINER, 2007).

$\mathrm{Na}$ perspectiva aqui defendida, a análise das relações possíveis entre a Educação Profissional e Tecnológica e o desenvolvimento regional não se pode ignorar a seguintes dimensões:

a) dimensão educativa - o desafio da Educação Profissional e Tecnológica e dos Institutos Federais é ir além das demandas de uma força de trabalho eficiente do ponto de vista exclusivamente do capital, em direção às conquistas da cidadania. Trata-se do recorrente debate em que, aqui, se destacam as posições que defendem uma formação holística, humanista, multidisciplinar, com capacidade analítica e crítica e sintonizada com a inserção cidadã - de democracia e direitos amplos - do trabalhador no projeto societal de desenvolvimento;

b) dimensão do desenvolvimento regional - não se pode desconsiderar as condições para a efetivação do desenvolvimento regional, presente na PNDR, dentre as quais destacam-se: integração entre políticas setoriais e entre os entes federativos, com a construção de instâncias intermediárias de governança entre as dimensões nacional e local, de base inter e intrarregionais, nas quais o país já desenvolve diversas experiências, abordadas por Siqueira (2015).

Mesmo considerando o longo, complexo e conflituoso caminho a percorrer, nas duas dimensões básicas aqui apontadas, acredita-se que seja possível avançar nos objetivos da Rede Federal relativos ao desenvolvimento regional e local, através das interações necessariamente geradas pela implantação desse equipamento no território, mormente nas localidades periféricas e nas localidades mais distantes, de pequeno e médio porte, uma vez que seus quadros dirigentes assumam a responsabilidade de formar os quadros docentes e administrativos nessa direção, permitindo desenvolver a sensibilidade, a percepção e a motivação para a inserção nos desafios e possibilidades existentes nas localidades onde estão implantados. É possível a contribuição dos Institutos Federais para o desenvolvimento, à escala local, micro e mesorregional, na perspectiva das políticas públicas e de iniciativas de alcance limitado, como defende (OLIVEIRA, 2001), sem cair no localismo, conforme abordado em Fernandez (2010). 


\section{CONSIDERAÇÕES FINAIS}

Neste artigo, pretendeu-se analisar, de forma bastante embrionária, as potencialidades de contribuição da política de expansão da educação profissional para o desenvolvimento regional, a partir dos objetivos definidos nos estatutos da expansão da Rede Federal de Educação Profissional e Tecnológica, a partir de 2003, e dos princípios da PNDR, tendo como pano de fundo a estrutura desigual do desenvolvimento territorial brasileiro.

A análise da política de expansão da educação profissional do governo federal, cujo ápice deliberativo e de implementação se deu entre 2003 e 2014, com ênfase na expansão da Rede Federal e na criação dos Institutos Federais, foi correlacionada à questão da sua orientação territorializada e regionalizada, e de integração com outras políticas públicas, na perspectiva do desenvolvimento regional.

A política federal de expansão e a criação dos Institutos Federais não fogem à defesa da educação humanística como direito fundamental, e, ao incorporar a questão territorial, considera que as possibilidades de mudar realidades requerem iniciativas e políticas que cheguem aos mais longínquos espaços do território nacional, dado o reconhecimento da heterogeneidade e desigualdades entre localidades, micro e mesorregiões, ampliando as possibilidades de escolhas. 0 artigo procurou evidenciar a não aleatoriedade na localização dos campi, na medida em que sintoniza, em linhas gerais, o perfil e as tendências da diferenciação espacial do desenvolvimento nos critérios que efetivaram sua implantação.

Sua capilaridade criteriosa, no entanto, não pode sucumbir à fragmentação das políticas públicas, mormente as de base territorial. Seu potencial reside nas possibilidades de integração com outras políticas, programas e ações públicas setoriais postas em curso, principalmente, pelos governos a partir de 2003 (mesmo que ameaçadas pela conjuntura pós-2016), que reforçam, em sua capilaridade, a interiorização e a regionalização, contribuindo para a redução da migração rumo às capitais e regiões metropolitanas. A existência da PNDR favorece a orientação no sentido dessa integração.

Os Institutos Federais não estão isentos de contradições e limites; eles refletem conflitos e confrontos de concepções presentes na sociedade. No entanto, é necessário reconhecer as suas possibilidades e sua importância como política projetada na direção da construção de um país mais integrado e menos desigual territorialmente, espacialmente mais democrático e justo. Potencialmente, à política de expansão e à criação dos Institutos Federais se opõe a lógica da localização concentrada e segregadora dos equipamentos públicos, da oferta de formação profissional em todos os níveis e, enfim, do acesso ao conhecimento e ao desenvolvimento cultural. Seus quadros dirigentes, docentes e técnico-administrativos deverão incorporar o debate sobre a construção do desenvolvimento às escalas local e regional, como dimensão de um projeto nacional de desenvolvimento.

Cabe registrar que a direção política e ideológica dessa política dependerá, ainda, do equacionamento do conflito atual entre o padrão de integração subordinada do país à economia internacional, apoiada na produção e exportação de produtos primários, do agronegócio, dos 
minérios, que, em grande medida, monopoliza a rede de infraestrutura e os recursos físicos e institucionais do país, produzindo um território fragmentado, do ponto de vista econômico e social, e um projeto nacional de integração regional e social.

A educação profissional acaba tendo sua concepção e finalidades disputadas por interesses mais e menos nacionais e integradores. Portanto, destaca-se a importância da profunda reflexão sobre o papel político dessas Instituições na construção do desenvolvimento inclusivo, integrador e cidadão. Sem esse compromisso, a educação profissional e tecnológica não escapará à formação de trabalhadores sob a égide exclusiva do mercado e do exacerbado individualismo dele derivado, que estimula a guerra de todos contra todos e a perda da alteridade e solidariedade sociais. Em última instância, sucumbe-se à fragmentação perdendo-se a dimensão da totalidade.

\section{REFERÊNCIAS}

ANTUNES, Ricardo. Trabalho e precarização numa ordem neoliberal. In: A cidadania negada. Buenos Aires: CLACSO, 2000, p. 35-48. Disponível em: $<$ http://bibliotecavirtual.clacso.org.ar/clacso/gt/20101010021549/3antunes.pdf.>. Acesso em: 18 jul. 2017.

BACELAR, Tânia. Tendências do Desenvolvimento Regional recente no Brasil. In: BRANDÃO, C.A.; SIQUEIRA, H. (Orgs.). Pacto Federativo, integração nacional e desenvolvimento regional. São Paulo: Editora Fundação Perseu Abramo, 2013, p. 39-51.

BRANDÃO, C.A. Avançamos na PNDR II, mas falta transformá-la em uma estratégia de Estado. Revista Política e Planejamento Regional, Rio de Janeiro, v. 1, n. 2, p. 339-344, dez. 2014.

BRASIL. Decreto № 7.566, de 23 de setembro de 1909. Cria nas capitães dos Estados da Republica Escolas de Aprendizes Artífices, para o ensino profissional primário e gratuito. Diário Oficial [da] República Federativa do Brasil. Poder Executivo, Brasília, DF, 26 set. 1909.

. Lei № 6.151, de 4 de dezembro de 1974. Dispõe sobre o Segundo Plano Nacional de Desenvolvimento (PND), para o período de 1975 a 1979. Diário Oficial [da] República Federativa do Brasil. Poder Executivo, Brasília, DF, 06 dez. 1974. Suplemento. Disponível em: <http://www.planalto.gov.br/ccivil_03/leis/1970-1979/anexo/ANL6151-74.PDF>. Acesso em: 20 fev. 2018.

Decreto $\mathrm{n}$ - 6.047, de 22 de fevereiro de 2007. Institui a Política Nacional de Desenvolvimento Regional - PNDR. Diário Oficial [da] República Federativa do Brasil. Poder Executivo, Brasília, DF, 23 fev. 2007.

- Decreto no 6.302, de 12 de dezembro de 2007. Institui o Programa Brasil Profissionalizado. Diário Oficial [da] República Federativa do Brasil. Poder Executivo, Brasília, DF, 13 dez. 2007.

Decreto no 6.047, de 22 de fevereiro de 2007. Institui a Política Nacional de Desenvolvimento Regional - PNDR. Diário Oficial [da] República Federativa do Brasil. Poder Executivo, Brasília, DF, 23 fev. 2007. 
. Lei no 11.892, de 29 de dezembro de 2008. Institui a Rede Federal de Educação Profissional, Científica e Tecnológica, cria os Institutos Federais de Educação, Ciência e Tecnologia, e dá outras providências. Diário Oficial [da] República Federativa do Brasil. Poder Executivo, Brasília, DF, 30 dez. 2008.

Secretaria Especial de Agricultura Familiar e do Desenvolvimento Agrário. Revista Territórios da Cidadania 2009. Brasília, 2009.

. Decreto no 7.589, de 26 de outubro de 2011. Institui a Rede e-Tec Brasil. Diário Oficial [da] República Federativa do Brasil. Poder Executivo, Brasília, DF, 27 out. 2011.

BRUNO, Lúcia. Educação e desenvolvimento econômico no Brasil. Revista Brasileira de Educação. v. 16, n. 48, set-dez. 2011.

Censo da Educação Básica. Disponível em: http://portal.inep.gov.br/educacao-basica>. Acesso em: 20 set. 2018.

CANO, Wilson. Raízes da Concentração Industrial em São Paulo. São Paulo: Difel, 1977.

Desconcentração produtiva regional do Brasil 1970-2005. São Paulo: Editora UNESP, 2008.

CASTRO, César Nunes de; BRANDÃO, Carlos Antonio (Orgs.). Desenvolvimento regional no Brasil: políticas, estratégias e perspectivas. Rio de Janeiro: Ipea, 2017, p. 277-305.

CASTRO, Sérgio Duarte de. Nova Política Nacional de Desenvolvimento Regional PNDR II. mar. 2013. 34 slides. Material apresentado na I Conferência Nacional de Desenvolvimento Regional. 2013.

CRUZ, José Luís Vianna da. Dinâmica socioeconômica e territorial no estado do Rio de Janeiro contemporâneo. In: GERSCHMAN, Silvia; SANTOS, Angela Moulin S. Penalva (Orgs.). Saúde e políticas sociais no Rio de Janeiro. Rio de Janeiro: Editora FIOCRUZ, 2016.

DINIZ, Clélio Campolina. A busca de um projeto de nação: o papel do território e das políticas regional e urbana. Revista EconomiA, Brasília, v. 7, n. 4, p. 1-18, dez. 2006.

FERNÁNDEZ, Victor Ramiro; BRANDÃO, Carlos. Escalas y políticas del desarrollo regional: desafíos para América Latina. Buenos Aires: Miño y Dávila Editores/UNL, 2010.

FURTADO, C. O Brasil pós-“milagre”. Rio de Janeiro: Paz e Terra, 1981.

LENCIONI, Sandra. (2015). Urbanização difusa e a constituição de megarregiões: o caso de São Paulo - Rio de Janeiro. Revista Eletrônica de Estudos Urbanos e Regionais: e-metropolis, n. 22, ano 6, p.6-15. Disponível em: <http://emetropolis.net/system/edicoes/arquivo_pdfs/000/000/022/original/emetropolis_n2 2.pdf?1447896390>. Acesso em: 28 dez. 2017. 
MANFREDINI, Denise. Ensaios sobre o II Plano de Desenvolvimento Econômico. 2015. Dissertação (Mestrado em Desenvolvimento Econômico) - Universidade Federal do Paraná, Curitiba, 2015.

OLIVEIRA, Francisco. Aproximações ao enigma: o que quer dizer desenvolvimento local? São Paulo: Polis, Programa Gestão Pública e Cidadania/EAESP/FGV, 2001.

OLIVEIRA, Hipólita Siqueira de. Desenvolvimento regional recente no Brasil/ Hipólita Siqueira. Rio de Janeiro-RJ. E-papers, 2010. 112p.

ORTIGARA, Claudino. Políticas para a educação profissional no Brasil: os Institutos Federais de Educação, Ciência e Tecnologia e a educação integral. Pouso Alegre: IFSul de Minas, 2014.

PIQUET, Rosélia. Indústria e território no Brasil contemporâneo. Rio de Janeiro: Garamond, 2007.

QUEIROZ, K. S.; SOUZA, F.C.S. O ensino técnico federal brasileiro no limiar da nova república: caminhos do PROTEC. HOLOS, ano 33, v. 3, p. 123-131, 2017.

RESENDE, Guilherme Mendes; MOREIRA, Paula Gomes; ALVES, Adriana Melo; NETO, João Mendes da Rocha. Brasil: dez anos da Política Nacional de Desenvolvimento Regional (PNDR). Boletim regional, urbano e ambiental, Brasília, v. 11, p. 29-35, jan-jun. 2015.

RUBIN. Gleisson. A Rede Federal de Educação Profissional e Tecnológica e a sua contribuição para o projeto de desenvolvimento nacional. In: GENTILI, Pablo (org.). Política educacional, cidadania e conquistas democráticas - São Paulo: Editora Perseu Abramo. 2013. 128 p.

SILVA, C. J. R. Institutos Federais lei 11.892, de 29/11/2008: comentários e reflexões / organização. Natal: IFRN, 2009.

SIQUEIRA, F. V. Noroeste Fluminense: arranjos regionais e perspectivas de desenvolvimento. Campos: Ucam. Dissertação de Mestrado, 2015.

SIQUEIRA, H. Dinâmica regional brasileira (1990-2012). In: BRANDÃO, C.A.; SIQUEIRA, H. (Orgs.). Pacto Federativo, integração nacional e desenvolvimento regional. São Paulo: Editora Fundação Perseu Abramo, 2013, p. 73-86.

TAVARES, M.C. Da substituição da importação ao capitalismo financeiro. Rio de Janeiro: Zahar, 1972.

VAINER, Carlos B. Planejamento territorial e projeto nacional: os desafios da fragmentação. Revista brasileira estudos urbanos e regionais, Rio de Janeiro, v. 9, n. 1, p. 9-23, mai. 2007.

VIEIRA, Danilo Jorge. Evolução do ensino superior brasileiro em período recente: novas perspectivas para o desenvolvimento regional? In: NETO, A.M.; CASTRO, C.N.; BRANDÃO, C.A. (Orgs.). Desenvolvimento regional no Brasil: políticas, estratégias e perspectivas: Ipea, 2017, p. 277-305. 